\title{
Oxygen therapy for critically III and post-operative patients
}

\author{
Paul J. Young ${ }^{1,2,3,4} \odot$. Daniel Frei ${ }^{1,5}$ \\ Received: 1 August 2021 / Accepted: 28 August 2021 / Published online: 6 September 2021 \\ (c) Japanese Society of Anesthesiologists 2021
}

\begin{abstract}
Nearly all patients receiving treatment in a peri-operative or intensive care setting receive supplemental oxygen therapy. It is biologically plausible that the dose of oxygen used might affect important patient outcomes. Most peri-operative research has focussed on oxygen regimens that target higher than normal blood oxygen levels. Whereas, intensive care research has mostly focussed on conservative oxygen regimens which assiduously avoid exposure to higher than normal blood oxygen levels. While such conservative oxygen therapy is preferred for spontaneously breathing patients with chronic obstructive pulmonary disease, the optimal oxygen regimen in other patient groups is not clear. Some data suggest that conservative oxygen therapy might be preferred for patients with hypoxic ischaemic encephalopathy. However, unless oxygen supplies are constrained, routinely aggressively down-titrating oxygen in either the peri-operative or intensive care setting is not necessary based on available data. Targeting higher than normal levels of oxygen might reduce surgical site infections in the perioperative setting and/or improve outcomes for intensive care patients with sepsis but further research is required and available data are not sufficiently strong to warrant routine implementation of such oxygen strategies.
\end{abstract}

Keywords Oxygen therapy $\cdot$ Hyperoxaemia $\cdot$ Intensive care $\cdot$ Perioperative care

\section{Introduction}

Supplemental oxygen is a common medical treatment but it is not necessarily a benign therapy. Humans evolved in an atmosphere with $21 \%$ oxygen and, from an evolutionary perspective, we are adapted to breathe room air and to a partial pressure of oxygen $\left(\mathrm{PaO}_{2}\right)$ in arterial blood of $75-100 \mathrm{mmHg}(10.5-13.5 \mathrm{kPa})$. Using oxygen to convert biochemical energy from nutrients into adenosine

Paul J. Young

paul.young@ccdhb.org.nz

1 Medical Research Institute of New Zealand, Private Bag 7902, Wellington 6242, New Zealand

2 Intensive Care Unit, Wellington Regional Hospital, Wellington, New Zealand

3 Australian and New Zealand Intensive Care Research Centre, Department of Epidemiology and Preventive Medicine, School of Public Health and Preventive Medicine, Monash University, Melbourne, VIC, Australia

4 Department of Critical Care, University of Melbourne, Parkville, VIC, Australia

5 Department of Anaesthesia, Wellington Regional Hospital, Wellington, New Zealand triphosphate (ATP) via aerobic cellular respiration is fundamental to sustaining human life.

While humans are dependent on oxygen to survive, oxygen is, inherently, a highly reactive chemical. In addition to producing ATP, aerobic cellular respiration produces reactive oxygen species (ROS). While these ROS have important roles in cellular signalling and homeostasis, they can damage nucleic acids, proteins and lipid membranes resulting in cell death. Antioxidant enzymes prevent major cellular damage from ROS. However, generation of ROS increases with rising $\mathrm{PaO}_{2}$ and, when production of ROS exceeds the capacity of the antioxidant enzymes, an imbalance known as "oxidative stress" results.

For clinicians in perioperative and intensive care unit (ICU) settings, determining the amount of oxygen to use involves balancing potential risks associated with exposure to oxygen levels that are either abnormally high or abnormally low. To some degree, liberal administration of oxygen risks exposing patients' cells and tissues to abnormally high levels of oxygen and, conversely, conservative administration of oxygen risks exposing patients' cells and tissues to abnormally low levels of oxygen. Key messages in relation to oxygen therapy regimens in different patient groups as described in this review are shown in Table 1. 
Table 1 Key messages in relation to oxygen therapy regimens in different patient groups and clinical situations

\begin{tabular}{|c|c|}
\hline Patient group/clinical situation & Key message \\
\hline Pre-oxygenation & $\begin{array}{l}\text { Preoxygenation is an accepted practice during the induction and emergence phases of anaesthesia to } \\
\text { prolong the apnoeic desaturation period to maximize the time for safe airway manipulation and place- } \\
\text { ment or removal of an airway device }\end{array}$ \\
\hline Maintenance of routine anaesthesia & $\begin{array}{l}\text { The optimal level of oxygen administration above that required to achieve safe oxygen saturation during } \\
\text { the maintenance phase of anaesthesia is uncertain }\end{array}$ \\
\hline To prevent surgical site infections & $\begin{array}{l}\text { It is not clear whether the oxygen therapy regimen used in the perioperative period affects the risk of } \\
\text { surgical site infection }\end{array}$ \\
\hline Acute respiratory distress syndrome & $\begin{array}{l}\text { Available data do not support the need to aggressively down-titrate oxygen in patients with ARDS or } \\
\text { with other causes of hypoxic respiratory failure }\end{array}$ \\
\hline Chronic obstructive pulmonary disease & Guidelines recommend targeting an $\mathrm{SpO}_{2}$ of $88-92 \%$ in patients with acute exacerbations of COPD \\
\hline Hypoxic ischaemic encephalopathy & $\begin{array}{l}\text { The optimal oxygen regimen to reduce death and disability in post cardiac arrest patients remains } \\
\text { uncertain }\end{array}$ \\
\hline Sepsis & $\begin{array}{l}\text { Further research is required to determine the optimal approach to oxygen therapy for patients with } \\
\text { sepsis and to establish whether a specific approach is needed for these patients }\end{array}$ \\
\hline $\begin{array}{l}\text { Traumatic brain injury, subarachnoid } \\
\text { haemorrhage, and stroke }\end{array}$ & $\begin{array}{l}\text { The optimal regimen for this patient group remains uncertain. It is unclear whether patients with brain } \\
\text { pathologies have different oxygen needs from other ICU patients }\end{array}$ \\
\hline
\end{tabular}

$A R D S$ acute respiratory distress syndrome, ICU intensive care unit, COPD chronic obstructive pulmonary disease

\section{Pathophysiology}

Normal physiology provides for extraction of oxygen from the atmosphere and delivery to cells. However, the concentration of oxygen that reaches cells is a fraction of that in the atmosphere due to a physiological cascade in which serial step decreases in oxygen tension occur from ambient air, through pulmonary, cardiac, macrovascular and microvascular systems before ultimately reaching the cell. This cascade results from anatomical and physicochemical barriers which create successive oxygen partial pressure gradients through diffusion of oxygen in the lung, binding of oxygen to haemoglobin in the blood, distribution to distant sites through the vasculature, dissociation of oxygen from haemoglobin and then diffusion into cells. This oxygen transport system serves to ensure delivery of oxygen to meet cellular metabolic demands, and to prevent excessive amounts of oxygen in cells that might overwhelm antioxidant capacity and cause oxidative stress. Oxygen tension in mitochondria, the intracellular organelles that produce energy through aerobic respiration, appears to be no greater than $5-10 \mathrm{mmHg}$. Interestingly, our mitochondria appear to have evolved from proteobacteria which were present when Earth's atmospheric oxygen pressures were likely to have been within this range [1].

Potential pathophysiological consequences of oxygen therapy relate both to the fraction of inspired oxygen $\left(\mathrm{FIO}_{2}\right)$ delivered to the lungs and to exposure of cells and their mitochondria to oxidative stress. In the lungs, supplemental oxygen therapy can promote resorption atelectasis [2]. In healthy humans, breathing $30 \%$ to $50 \%$ oxygen for $45 \mathrm{~h}$ leads to lung injury with leakage of proteinaceous material into the alveolae [3]. In baboons, sustained exposure to $\mathrm{FIO}_{2} 0.60$, as may occur with invasive ventilation of a critically ill patient in the ICU, leads to pulmonary toxicity with alveolitis, hyaline membrane formation, cellular infiltration, pulmonary oedema and subsequently lung scarring [4]. In practice, clinical recognition of pulmonary oxygen toxicity is often difficult because clinical assessment is an insensitive method of identifying oxygeninduced pathological injury and because clinical features of oxygen-induced lung injury overlap with those of the diseases that result in a requirement for oxygen therapy.

At the cellular level, exposure to high oxygen tension is potentially toxic if production of ROS is in excess of physiological antioxidant defence capability. This imbalance is known as oxidative stress. ROS are constantly generated in the mitochondria as oxygen is reduced along the electron transport chain. ROS have important roles in normal cellular function but they can be toxic to cells as they possess an unpaired electron. Because of this unpaired electron, they are highly reactive and have the potential to damage macromolecules including lipids, proteins and nucleic acids. Despite these theoretic concerns, the relationship between oxygen therapy and free radical generation in clinical practice is not certain. For example, in one study conducted in critically ill patients, conservative oxygen therapy did not significantly alter plasma concentrations of the antioxidant ascorbate or biomarkers of lipid or protein oxidation compared to standard oxygen therapy [5]. From a pathophysiological perspective, there are a number of potential explanations for this. One explanation is that standard oxygen therapy may not represent an important source of oxidative stress in the critically ill; it is plausible that other sources of oxidative stress predominate in such patients. Alternatively, 
it may be that even conservative use of oxygen results in oxidative stress, and that degree of stress is similar to that seen with liberal oxygen therapy. The effect of oxygen regimens on oxidative stress in the perioperative setting are uncertain.

\section{Oxygen therapy in perioperative care- general considerations}

Approximately 300-400 million people undergo surgery across world every year [6]. The majority of patients having surgery under general anaesthesia will receive an $\mathrm{FIO}_{2}$ at levels higher than that found in room air. There are several possible reasons why anaesthetists administer supra-atmospheric $\mathrm{FIO}_{2}$ in routine anaesthesia care.

\section{Preoxygenation}

Preoxygenation is an accepted practice during the induction and emergence phases of anaesthesia to prolong the apnoeic desaturation period to maximize the time for safe airway manipulation and placement or removal of an airway device. Increasing $\mathrm{FIO}_{2}$ to close to 1.0 can achieve an endtidal fraction of oxygen near to 0.9 , thus replacing the nitrogen component of air in the lungs with oxygen and creating an intrapulmonary oxygen store equivalent to the functional residual capacity. This prolongs apnoeic desaturation time from approximately one up to eight minutes in healthy volunteers [7].

\section{Intraoperative crises}

Maintaining high $\mathrm{FIO}_{2}$ during surgery might offer a margin of safety by providing a longer time to desaturation in the event of inadvertent extubation, rapid respiratory deterioration, equipment failure, or other unexpected issue. On the other hand, maintaining a high $\mathrm{FIO}_{2}$ could delay recognition of a failure of oxygenation and potential evolving crisis and render the anaesthetist unable to increase $\mathrm{FIO}_{2}$ in response. Administering a lower $\mathrm{FIO}_{2}$, such as the minimum $\mathrm{FIO}_{2}$ required to provide safe saturations, may alert the anaesthetist to changes in the patient's condition by observing changes in $\mathrm{SpO}_{2}$, enabling earlier intervention and the ability to increase $\mathrm{FIO}_{2}$ as a temporizing measure.

\section{$\mathrm{FIO}_{2}$ during the maintenance phase of routine anaesthesia care}

An $\mathrm{FIO}_{2}$ above 0.21 may be required to maintain safe arterial blood oxygen saturation to overcome the effects of atelectasis, reduced FRC and altered ventilation/perfusion matching among other changes that occur under anaesthesia for major surgery. However, the optimal level of oxygen administration above that required to achieve safe oxygen saturation during the maintenance phase of anaesthesia is unknown, and existing guidelines are conflicting. The World Health Organisation (WHO) recommends provision of liberal intraoperative oxygen $\left(\mathrm{FIO}_{2} \geq 0.8\right)$ for the purpose of reducing postoperative surgical site infection (SSI) [8]. In contrast, the World Federation of Societies of Anesthesiologists (WFSA) suggest administering a much lower intraoperative $\mathrm{FIO}_{2}$ $(0.30-0.40)$ in patients having general anaesthesia with tracheal intubation, and titrated postoperative oxygen therapy to maintain $\mathrm{SpO}_{2}>93 \%$, consistent with British Thoracic Society oxygen guidelines $[9,10]$.

In a recent survey of Australian and New Zealand anaesthetists, $58 \%$ of respondents reported titrating $\mathrm{FIO}_{2}$ to achieve a level of oxygenation that they feel is safe, $29 \%$ aim to minimize $\mathrm{FIO}_{2}$ and 5\% aim to maximize intraoperative $\mathrm{FIO}_{2}$ [11]. The average self-reported targeted intraoperative $\mathrm{FIO}_{2}$ in this study was $0.41 \pm 0.12$; however self-reporting is prone to bias and this may not accurately reflect real-world practice [12]. The iOPS study observed anaesthetists caring for patients during surgery under general anaesthesia with insertion of invasive blood pressure monitoring and reported a mean intraoperative $\mathrm{FIO}_{2}$ of 0.49 [13]. A5-day cross-sectional observational study of 1498 patients undergoing general anaesthesia in 43 hospitals in Japan reported a median $\mathrm{FiO}_{2}$ one hour after induction of anaesthesia was 0.47 (interquartile range $0.4-0.6$ ) [14] A large retrospective registry study investigating a potential association between intraoperative $\mathrm{FIO}_{2}$ and major respiratory complications in 73,992 adult patients undergoing non-cardiac surgery under general anaesthesia reported an overall average $\mathrm{FIO}_{2}$ administered of 0.52 [15].

\section{Oxygen therapy in perioperative care- specific situations}

\section{Surgical site infection}

In 2000, on the basis previous work demonstrating an association between low tissue partial pressure of oxygen $\left(\mathrm{PaO}_{2}\right)$ and postoperative SSI, Grief and colleagues conducted a trial investigating the impact of perioperative $\mathrm{FIO}_{2}$ on SSI [16]. A total of 500 patients undergoing colorectal surgery were randomly assigned to an $\mathrm{FIO}_{2}$ of 0.30 or 0.80 . Higher $\mathrm{FIO}_{2}$ reportedly reduced SSI by 6.0 percentage points [95\% confidence interval (CI), 1.2-10.8 percent]. These findings were reinforced in a subsequent trial of 300 patients undergoing colorectal surgery where a relative risk of SSI of 0.46 (95\% CI 0.22-0.95) was reported in patients who received higher compared to lower oxygen [17]. The ENIGMA trial was designed primarily to assess the safety of nitrous oxide $\left(\mathrm{N}_{2} \mathrm{O}\right)$-based anaesthesia, by evaluating the impact of $80 \%$ 
$\mathrm{O}_{2} / 20 \%$ nitrogen versus $70 \% \mathrm{~N}_{2} \mathrm{O} / 30 \% \mathrm{O}_{2}$ gas mixture on duration of hospital stay and a range of secondary outcomes [18]. Although there was no difference in the primary outcome, patients in the $\mathrm{N}_{2} \mathrm{O}$-free group had a lower incidence of postoperative wound infection. The ENIGMA trial has been used to support the use of liberal perioperative oxygen therapy and has been included in most meta-analyses to date; however, the trial authors do not consider this an appropriate application of the trial evidence given the study was not designed to assess this [19].

The PROXI trial investigated the effect of an $\mathrm{FIO}_{2}$ of 0.30 vs 0.80 on SSI and pulmonary complications and showed no difference in SSI within 14 days of surgery, or any of the secondary outcomes including atelectasis, pneumonia, respiratory failure and mortality [20]. A $2 \times 2$ factorial design trial of 586 patients investigating the effect an $\mathrm{FIO}_{2}$ of 0.30 vs 0.80 and dexamethasone vs placebo similarly showed no difference in the primary outcome of SSI within 30 days of surgery; however there were more deep wound infections and a longer duration of hospital admission in the $\mathrm{FIO}_{2}$ 0.80 group [21]. A cluster-cross over trial of 5749 patients undergoing colorectal surgery at a single centre showed no statistically significant difference in SSI or any of other outcome when comparing $\mathrm{FIO}_{2}$ of 0.30 vs 0.80 [22]. The most recent trial compared the effects of $\mathrm{FIO}_{2}$ of 0.30 vs 0.80 on SSI during an individualized perioperative open-lung ventilatory strategy (iPROVE) [23]. Amongst 740 participants undergoing abdominal surgery recruited at 21 sites, there was no difference in SSI rates, or any secondary outcome.

The WHO meta-analysis that formed the basis of their recommendation for liberal oxygen therapy included 15 studies undergoing colorectal and mixed surgical types under general or neuraxial anaesthesia. The main analysis of $\mathrm{FIO}_{2} 0.80$ vs 0.30 to 0.35 revealed no evidence of benefit or harm. However, a subgroup analysis of patients undergoing surgery under general anaesthesia with tracheal intubation resulted in a significantly lower rate of SSI among patients assigned to an $\mathrm{FIO}_{2}$ of 0.80 . This finding was more pronounced in patients undergoing colorectal surgery [8]. The WHO recommendation was recently down-graded from 'strong to 'conditional' after two of the studies included in their meta-analysis were found to be fraudulent [24, 25]. A Cochrane systematic review and meta-analysis performed at a similar time found no evidence of a beneficial effect of an $\mathrm{FIO}_{2}$ of 0.80 compared to an $\mathrm{FIO}_{2}$ of 0.30 to 0.35 [26]. The authors of this review did not perform a subgroup analysis of patients with tracheal intubation, as they did not consider there to be a biologically plausible reason for liberal oxygen therapy to have a differential therapeutic benefit in this subgroup only.

The largest meta-analysis evaluating oxygen regimens in the perioperative setting included 26 trials and a total of 14,710 patients [27]. Overall, the RR for wound infection in the high vs low $\mathrm{FIO}_{2}$ groups was 0.81 (95\% CI 0.70-0.94). When studies with a high risk of bias were excluded, high $\mathrm{FIO}_{2}$ did not significantly reduce SSI compared to low $\mathrm{FIO}_{2}$. A recent meta-analysis focussed on evaluating the safety of $\mathrm{FIO}_{2}$ of 0.80 compared to $\mathrm{FIO}_{2}$ of $0.30-0.35$ in the perioperative setting by reviewing all clinically relevant adverse events in available perioperative oxygen trials [28]. The authors concluded there was no evidence of increased harm with liberal oxygen therapy; however, they noted that data related to adverse outcomes were sparsely and inconsistently recorded, so that available data constituted low quality of evidence.

\section{Oxygen therapy in perioperative care- future directions}

While there is uncertainty about the potential benefit of liberal oxygen therapy on reduction of SSI, it is also not known whether any potential beneficial effect of liberal oxygen could be offset by increased risk of harm by other, noninfection related postoperative complications. Future studies are needed to assess the net effect of differing regimens of oxygen therapy on patient-centred outcomes, as well as on individual postoperative complications. This assertion is supported by previous studies that have suggested possible associations between a liberal strategy of intraoperative oxygen administration and decreased postoperative cancerfree survival and time to recurrent cancer diagnosis [29], increased risk of myocardial infarction, acute coronary syndrome and death [30].

While it is broadly accepted that persistent extreme hypoxia or hyperoxia are likely to cause harm, the nature of the relationship of inspired oxygen and specific outcomes is less certain. Furthermore, the relationship between $\mathrm{FiO}_{2}$ within the range of $0.30-0.80$ and any outcome may not be linear. A recent study investigated the effect of varying levels of $\mathrm{FIO}_{2}$ on renal cortical and medullary tissue perfusion and oxygen tension $\left(\mathrm{PtO}_{2}\right)$ in sheep undergoing abdominal surgery [31]. $\mathrm{PtO}_{2}$ was equal to preoperative values with $\mathrm{FIO}_{2}$ 0.40-0.60. At $\mathrm{FIO}_{2} 0.21, \mathrm{PtO}_{2}$ was significantly less than at baseline, and at $\mathrm{FIO}_{2} 1.0, \mathrm{PtO}_{2}$ was significantly higher than baseline. It is, therefore, possible that an intermediate level of $\mathrm{FIO}_{2}$ may represent the optimum level for patients undergoing surgery under general anaesthesia, as this may most closely represent physiological conditions at the cellular level. Anaesthesia trials that incorporate in intermediate treatment arm between the extremes of an $\mathrm{FIO}_{2}$ of 0.80 and an $\mathrm{FIO}_{2}$ of 0.30 are, therefore, needed. Additionally, in future studies oxygen may be able to be titrated to achieve different levels of arterial or tissue oxygenation exposure, arguably enabling more precise targeting of cellular oxygen exposure. 


\section{Oxygen therapy in intensive care-general considerations}

The Oxygen-ICU trial [32], a single-centre RCT conducted in Italy included 480 patients expected to stay in ICU for at least $72 \mathrm{~h}$ who were allocated to conservative or conventional oxygen therapy. A total of $20.2 \%$ and $11.6 \%$ of conventional and conservative oxygen therapy patients, respectively, died in the ICU. With only around two-thirds of the patients included in the study mechanically ventilated at baseline and a third having shock, the illness acuity of enrolled patients was relatively low. ICU mortality, was statistically significantly lower among patients allocated to conservative oxygen therapy; however, the study was stopped early after an interim analysis not planned a priori [32]. Given the variety of mechanisms of death in ICU patients [33], it seems unlikely that such a high proportion of deaths in a heterogeneous population of ICU patients could be attributable to the dose of oxygen therapy used. However, the IOTA systematic review and meta-analysis [34] also reported that conservative use of oxygen in acutely ill adults significantly reduced in-hospital mortality. Based largely on this analysis, a clinical practice guideline was published in the BMJ and made a strong recommendation for maintaining an oxygen saturation of no more than $96 \%$ in acutely ill medical patients (upper limit) [35].

Although the IOTA study findings were concordant with the Oxygen-ICU trial [32], they provided only low certainty evidence on the question of whether conservative use of oxygen truly reduced mortality either in ICU patients or in acutely ill adults more generally for a number of reasons [36]. First, the Oxygen-ICU trial [32] contributed $32 \%$ of the weight to the mortality analysis. Second, the predominant diagnoses in patients included in this analysis were acute myocardial infarction and stroke, and a range of oxygen regimens were tested so that the analysis provided only indirect evidence about the optimal oxygen regimen for patients in the ICU. Finally, the overall mortality treatment effect estimates were imprecise.

The ICU Randomised Trial comparing two approaches to Oxygen therapy (the ICU-ROX trial) compared conservative oxygen therapy and usual (liberal) oxygen therapy in adults who were invasively mechanically ventilated and anticipated to be ventilated beyond the calendar day after randomization [37]. Conservative oxygen therapy did not significantly affect ventilator-free days, compared with usual (liberal) oxygen therapy. Overall, $35.7 \%$ and $34.5 \%$ of patients allocated to conservative oxygen and usual oxygen therapy, respectively, died by day 180 with a corresponding odds ratio of death of 1.05 (95\% CI 0.81-1.37). While these findings provide some reassurance to clinicians about the safety of the liberal use of oxygen that occurs in standard practice, they do not exclude clinically important effects of the oxygen regimens tested on mortality risk. While it seems prudent to avoid both extreme hypoxaemia and extreme hyperoxemia, the most appropriate dose of oxygen to give to critically ill adults patients in the ICU remains uncertain. Furthermore, whether or not conservative oxygen therapy affects mortality overall, it is plausible that a particular oxygen regimen might benefits some patient groups and harms others.

\section{Oxygen therapy in intensive care-specific situations}

\section{Acute Respiratory Distress Syndrome (ARDS) and other causes of hypoxic respiratory failure}

Patients with acute lung diseases including ARDS and pneumonia almost always require supplemental oxygen to prevent arterial hypoxemia. For this group of patients, many factors might affect the optimal oxygen regimen. Even when a conservative approach to oxygen therapy is adopted, achieving a safe minimum arterial oxygen level may require a high $\mathrm{FIO}_{2}$ and lead to pulmonary oxygen toxicity. Oxygen can impair alveolar macrophage function and promote ventilation/perfusion mismatch. While giving oxygen liberally may worsen these effects, patients with lung pathologies can desaturate rapidly and unexpectedly due to problems like sputum plugging or ventilator dyssynchrony. The risk of unanticipated periods of hypoxaemia in a group of patients with limited respiratory reserve, might favour a relatively liberal approach. However, when oxygen is given liberally in patients with lung diseases, supranormal arterial oxygen levels can occur. Such supranormal oxygen levels represent a physiological stressor and might potentially worsen patient outcomes.

The Liberal Oxygenation versus Conservative Oxygenation in Acute Respiratory Distress Syndrome $\left(\mathrm{LOCO}_{2}\right)$ trial compared conservative oxygen therapy with liberal oxygen therapy in patients with ARDS [38]. This trial was stopped early at an unplanned interim analysis after recruitment of 205 patients because of concern about intestinal ischaemia events and deaths in the conservative oxygen therapy group. While patients with ARDS represent an important subset of patients with hypoxic respiratory failure, there is no evidence (or particular reason to believe) that patients with ARDS are more or less prone to pulmonary oxygen toxicity or to the systemic effects of hypoxaemia than patients with lung pathologies who do not have ARDS. The ICU-ROX trial included 623 patients with hypoxic respiratory failure as identified by a PF ratio of less than $300 \mathrm{mmHg}$. In relation to the ICU-ROX trial primary end point, alive ventilator-free 
days, there was no evidence of heterogeneity of treatment effect for patients with a PF ratio of less than $300 \mathrm{mmHg}$ compared to those with a $\mathrm{PF}$ ratio of $300 \mathrm{mmHg}$ or more [37]. There was also no statistically significant difference in ventilator free days by treatment group for patients with a low PF ratio who were assigned to conservative oxygen therapy or usual oxygen therapy in the ICU-ROX trial. The Handling Oxygenation Targets in the ICU (HOT-ICU) trial assigned 2928 adults with acute hypoxemic respiratory failure to receive oxygen therapy targeting an arterial partial pressure of oxygen $\left(\mathrm{PaO}_{2}\right)$ of $60 \mathrm{mmHg}$ (lower-oxygenation group) or $90 \mathrm{mmHg}$ (higher-oxygenation group) [39]. At 90 days, there was no statistically significant difference in mortality between the lower-oxygenation group and higheroxygenation groups with $42.9 \%$ and $42.4 \%$, respectively, having died.

Overall, the available data from RCTs do not support the need to aggressively down-titrate oxygen in patients with ARDS or with other causes of hypoxic respiratory failure [40]. However, for situations where availability of oxygen is constrained due to high demand and/or constrained supply, as has been the case in some countries during the COVID-19 pandemic, implementation of conservative oxygen therapy regimens for patients with hypoxic respiratory failure to preserve oxygen supply appears reasonable [40]. Nevertheless, it is important to note that even the largest trial in patients with hypoxic respiratory failure, the HOT-ICU trial, was designed to test the hypothesis that conservative oxygen therapy would reduce 90 day mortality by an absolute margin of 5 percentage points [39]. Although an effect of this magnitude now appears very unlikely, a smaller, but still clinically important, effect on mortality cannot be excluded.

\section{Chronic Obstructive Pulmonary Disease (COPD) and other diseases associated with hypercapnic respiratory failure}

Oxygen therapy guidelines recommend targeting an $\mathrm{SpO}_{2}$ of $88-92 \%$ in patients with acute exacerbations of COPD [41, 42]. These recommendations were influenced, in large part, by the findings of a RCT of liberal versus titrated oxygen therapy in patients with severe exacerbations of emphysema and chronic bronchitis in the pre-hospital setting [43]. The conservative oxygen regimen had two components: titrated supplementary oxygen if required to achieve an $\mathrm{SpO}_{2}$ of $88 \%$ to $92 \%$ and the use of bronchodilators delivered by an air-driven nebuliser. The liberal oxygen regimen had two components-high flow oxygen therapy at 8-11 L/min and bronchodilators delivered by nebulisation with oxygen flows of $6-8 \mathrm{~L} / \mathrm{min}$. Titrated oxygen reduced mortality by $58 \%$ for all patients included in the study and by $78 \%$ for all patients with confirmed COPD. The liberal oxygen regimen was associated with more severe respiratory acidosis and hypercapnia, which likely contributed to the mortality risk as most deaths were due to respiratory failure. Since this initial report, similar increases in $\mathrm{PaCO}_{2}$ with liberal oxygen therapy have been demonstrated in a range of other acute respiratory conditions including asthma [44, 45], pneumonia [46] and chronic respiratory conditions such as obesity hyperventilation syndrome [46]. The likely mechanisms for this physiological effect are worsening ventilation/perfusion mismatch because of overcoming hypoxic pulmonary vasoconstriction and a reduction in ventilatory drive.

A total of 565 patients with COPD were included in the HOT-ICU trial [39]. Among these patients, $44.0 \%$ allocated to low oxygen and $46.3 \%$ allocated to high oxygen had died by day 90 . This was not a significant difference and there was no statistically significant heterogeneity of treatment response for COPD patients compared to non-COPD patients. These findings contrast with those of the previous pre-hospital trial [43]. The apparent difference may reflect the fact that intervention to treat worsening hypercapnic respiratory failure with non-invasive or invasive ventilation is straightforward in the ICU setting.

Given the reproducible physiological effect of liberal oxygen therapy on $\mathrm{pCO}_{2}$ levels in spontaneously breathing patients, clinicians may prefer to implement conservative oxygen therapy where there is concern about the potential for liberal oxygen therapy to worsen hypercapnic respiratory failure. However, for patients who are invasively ventilated, there are no RCTs demonstrating that specific oxygen therapy regimens improve outcomes in patients with COPD or in other diseases associated with hypercapnic respiratory failure.

\section{Sepsis}

Sepsis is a common reason for ICU admission and many patients with sepsis receive supplemental oxygen. The presence of infection may be a relevant consideration when deciding how liberally to give oxygen. The body's ability to fight infection might be enhanced with liberal use of oxygen via enhanced oxidative killing of bacteria because neutrophil superoxide production increases in the presence of high oxygen tension. Fundamentally, the neutrophil's "oxidative burst" requires oxygen.

In a post-hoc analysis of the ICU-ROX trial, the 90-day mortality rate for patients treated with usual (liberal) oxygen was seven percentage points lower than it was for patients who received conservative oxygen therapy [47]. While this was not a statistically significant difference, the analysis population was small, and the potential for clinically relevant benefit (or indeed harm) with liberal provision of oxygen to patients with sepsis cannot be excluded. That said, data from the Hyper2S trial [48] suggest that therapeutic hyperoxemia using an $\mathrm{FIO}_{2}$ of 1.0 should not be used routinely in patients 
with septic shock. The Hyper2Strial, which evaluated therapeutic hyperoxemia and 3\% saline in a factorial design in patients with septic shock, was terminated early because of a statistically significant increase in serious adverse events in the hyperoxemia group [48]. Although the difference was not statistically significant, 28-day mortality was eight percentage points higher for patients assigned to hyperoxemia than for those assigned to normoxia.

Further research is required to determine the optimal approach to oxygen therapy for patients with sepsis and to establish whether a specific approach is needed for these patients. Moreover, although specific evidence from RCTs is lacking, because of direct pulmonary oxygen toxicity, it is possible that patients with lung pathologies and sepsis might have different oxygen requirements than patients with sepsis who do not have lung pathologies.

\section{Hypoxic ischaemic encephalopathy (HIE)}

HIE involves a "two-hit" injury [49]. A primary injury occurs as a result of immediate cessation of cerebral oxygen delivery and is followed by a secondary injury occurring after resuscitation [49]. This secondary injury is, in part, the result of oxygen free radical production leading to intracellular oxidation and cellular injury [49]. While endogenous antioxidants can offset the effect of generation of free radicals and stabilise cellular function following restoration of blood flow to the brain, liberal provision of oxygen might tip the balance in favour of free radical production, cellular oxygenation and neuronal death. In animal trials investigating different fractions of inspired oxygen in animal models of cardiac arrest with cardiopulmonary resuscitation [50], animals allocated to $100 \%$ oxygen had more neuronal damage, greater levels of cerebral metabolic dysfunction and worse neurological deficits than those allocated to lower concentrations of oxygen [50].

ICU-ROX included 166 participants with suspected HIE following cardiac arrest. In this subgroup, a total of $43 \%$ assigned conservative oxygen and 59\% assigned to liberal oxygen died by 180 days (relative risk $0.73 ; 95 \%$ CI $0.54-0.99 ; P=0.04$ ) [37]. A total of $45 \%$ of the patients with HIE assigned to conservative oxygen and $32 \%$ assigned to usual (liberal) oxygen had a favourable outcome on the Extended Glasgow Outcome Scale at 180 days, defined as an outcome of lower moderate disability or better (relative risk 1.23 ; 95\% CI $0.95-1.59 ; P=0.13)$.

In a subsequent post-hoc analysis that included the patients with HIE from the ICU-ROX trial [51], important baseline covariates that predict outcome in cardiac arrest patients were collected. Although baseline variables were not statistically significantly different by treatment group, many baseline covariates strongly predict adverse outcomes in this patient group [52] and, in an analysis adjusting for these baseline covariates, the confidence interval around the treatment estimate for the effect of conservative oxygen therapy on survival with favourable neurological outcome at day 180 was sufficiently wide that it encompassed both clinically important benefit and harm [adjusted odds ratio 1.85 (95\% CI 0.79-4.34); $P=0.15$ ] [51].

An individual patient level data meta-analysis incorporating data from seven RCTs of conservative vs. liberal oxygen therapy in cardiac arrest patients demonstrated that mortality at last follow-up was lower in patients allocated to conservative oxygen therapy, even after adjustment for baseline covariates (adjusted OR 0.58; 95\% CI 0.35-0.96; $P=0.04$ ) [53]. However, despite statistically significant findings, based on the GRADE classification [54], these data represent low or very low certainty evidence due to a risk of bias, imprecision and indirectness. Very few included studies $[51,55]$ had data on post-hospital discharge neurological outcomes further emphasising the degree of uncertainty. The HOT ICU trial included 332 patients who were admitted to the ICU after a cardiac arrest [39]. A total of $65.3 \%$ and $60.0 \%$ of those allocated to the lower oxygenation group and higher oxygenation group, respectivel,y died by day 90 . Functional outcome data for cardiac arrest patients enrolled in the HOT ICU trial have not been reported. There are two ongoing pre-hospital trials seeking to evaluate oxygen therapy in cardiac arrest patients (the EXACT trial [56] and the PROXY trial [57]). The effect of conservative oxygen therapy on survival with favourable mortality at 6 months in ICU patients with suspected hypoxic ischaemic encephalopathy is being investigated in the Low OxyGen Intervention for Cardiac Arrest Injury Limitation (LOGICAL trial) [58]. While some prior observational studies have suggested that exposure to hyperoxemia is associated with increased mortality risk among post-cardiac arrest patients, the results RCTs indicate that the optimal oxygen regimen to reduce death and disability in post cardiac arrest patients remains uncertain.

\section{Traumatic brain injury, subarachnoid haemorrhage and stroke}

One of the guiding principles of neuro-intensive care is that ischaemia is a major cause of secondary brain injury. Despite this, apart from in patients with HIE, there are very few data from clinical trials evaluating the optimal oxygen regimen in neurocritical care patients. In the ICU-ROX trial [37], patients with acute brain pathologies (including HIE) were a pre-specified subgroup; however, findings in relation to brain-injured patients who did not have HIE have not been reported. It is notable that in patients with traumatic brain injury in particular, brain tissue oxygenation levels are often lower than normal and such low brain tissue oxygenation levels are associated with worse outcomes. Liberal 
provision of oxygen increases brain tissue oxygenation levels but its effects on patient outcomes is unknown. As there are currently no data from RCTs evaluating oxygen regimens for neuro-intensive care patients, the optimal regimen for this patient group remains uncertain and it remains unclear whether or not patients with brain pathologies have different oxygen needs from other ICU patients.

\section{Oxygen therapy in intensive care-future directions}

Further research is needed to define the optimal oxygen regimen for intensive care patients. Given that many hundreds of thousands of patients receive mechanical ventilation in ICU every year, an absolute reduction in mortality of even 1.5 percentage points attributable to the oxygen therapy regimen of choice would have profound importance for global health [59]. For every 100,000 patients treated, this would equate to 1500 lives saved. The Mega-ROX trial, which is currently recruiting, will test the hypothesis that compared with liberal oxygen therapy targets, conservative oxygen therapy reduces mortality by 1.5 percentage points in adult ICU patients who are ventilated in ICU following an emergency admission or who are emergently intubated in the ICU. This 40,000-participant trial is being conducted in many countries. Because it is possible that conservative oxygen therapy will be best for patients with some diagnoses while liberal oxygen will be best for patients with other diagnoses (i.e. that there will be heterogeneity of treatment effect), a number of parallel nested trials will be conducted within the overall 40,000 participant trial sample. Each of these nested trials will evaluate a pre-specified hypothesis in specific cohorts of critically ill patients (i.e. patients with sepsis, patients with HIE and patients with other brain pathologies) and is accompanied by a separate power calculation.

\section{Conclusion}

Supplemental oxygen therapy is one of the most common treatments in the perioperative and ICU setting. While it is highly plausible that the oxygen regimen used might affect patient outcomes, the optimal regimen is not yet certain and may well differ depending on the clinical circumstances. Most research in the ICU has focussed on minimizing oxygen exposure while, in anaesthesia, interventions that increase oxygen exposure have been the principal subject of investigation.

Currently, a reasonable approach in ICU patients is to aim for arterial oxygen levels that are within the normal range. In the peri-operative setting a broader range of arterial oxygen levels encompassing values that are higher than normal is reasonable. However, in both situations, it is highly likely that further clinical trials will further our understanding and alter recommendations in the future.

\section{References}

1. Hsia CC, Schmitz A, Lambertz M, Perry SF, Maina JN. Evolution of air breathing: oxygen homeostasis and the transitions from water to land and sky. Compr Physiol. 2013;3(2):849-915.

2. Suzuki S, Eastwood GM, Goodwin MD, Noe GD, Smith PE, Glassford N, Schneider AG, Bellomo R. Atelectasis and mechanical ventilation mode during conservative oxygen therapy: A before-and-after study. J Crit Care. 2015;30(6):1232-7.

3. Griffith DE, Holden WE, Morris JF, Min LK, Krishnamurthy GT. Effects of common therapeutic concentrations of oxygen on lung clearance of 99mTc DTPA and bronchoalveolar lavage albumin concentration. Am Rev Respir Dis. 1986;134(2):233-7.

4. Fracica PJ, Knapp MJ, Piantadosi CA, Takeda K, Fulkerson WJ, Coleman RE, Wolfe WG, Crapo JD. Responses of baboons to prolonged hyperoxia: physiology and qualitative pathology. J Appl Physiol (1985). 1991;71(6):2352-62.

5. Carr AC, Spencer E, Mackle D, Hunt A, Judd H, Mehrtens J, Parker K, Stockwell Z, Gale C, Beaumont M, Kaur S, Bihari S, Young PJ. The effect of conservative oxygen therapy on systemic biomarkers of oxidative stress in critically ill patients. Free Radic Biol Med. 2020;160:13-8.

6. Weiser TG, Haynes AB, Molina G, Lipsitz SR, Esquivel MM, Uribe-Leitz T, Fu R, Azad T, Chao TE, Berry WR, Gawande AA. Size and distribution of the global volume of surgery in 2012. Bull World Health Organ. 2016;94(3):201-9.

7. Edmark L, Kostova-Aherdan K, Enlund M, Hedenstierna G. Optimal oxygen concentration during induction of general anesthesia. Anesthesiology. 2003;98(1):28-33.

8. Allegranzi B, Zayed B, Bischoff P, Kubilay NZ, de Jonge S, de Vries F, Gomes SM, Gans S, Wallert ED, Wu X, Abbas M, Boermeester MA, Dellinger EP, Egger M, Gastmeier P, Guirao X, Ren J, Pittet D, Solomkin JS, Group WHOGD. New WHO recommendations on intraoperative and postoperative measures for surgical site infection prevention: an evidence-based global perspective. Lancet Infect Dis. 2016;16(12):e288-303.

9. Mellin-Olsen J, McDougall RJ, Cheng D. WHO Guidelines to prevent surgical site infections. Lancet Infect Dis. 2017;17(3):260-1. https://doi.org/10.1016/S1473-3099(17)30078-6.

10. O'Driscoll BR, Howard LS, Earis J, Mak V, British Thoracic Society Emergency Oxygen Guideline Group. BTS guideline for oxygen use in adults in healthcare and emergency settings. Thorax. 2017;72(Suppl 1):ii1-90.

11. Frei DR, Beasley R, Campbell D, Leslie K, Merry AF, Moore M, Myles PS, Ruawai-Hamilton L, Short TG, Young PJ. Practice patterns and perceptions of Australian and New Zealand anaesthetists towards perioperative oxygen therapy. Anaesth Intensive Care. 2019;47(3):288-94.

12. Adams AS, Soumerai SB, Lomas J, Ross-Degnan D. Evidence of self-report bias in assessing adherence to guidelines. Int J Qual Health Care. 1999;11(3):187-92.

13. Morkane CM, McKenna H, Cumpstey AF, Oldman AH, Grocott MPW, Martin DS, Pan London Perioperative A, Research N. Intraoperative oxygenation in adult patients undergoing surgery (iOPS): a retrospective observational study across 29 UK hospitals. Perioper Med (Lond). 2018;7:17.

14. Suzuki S, Mihara Y, Hikasa Y, Okahara S, Ishihara T, Shintani A, Morimatsu H, Sato A, Kusume S, Hidaka H, Yatsuzuka H, Okawa M, Takatori M, Saeki S, Samuta T, Tokioka H, Kurasako 
T, Maeda M, Takeuchi M, Hirasaki A, Kitaura M, Kajiki H, Kobayashi O, Katayama H, Nakatsuka H, Mizobuchi S, Sugimoto S, Yokoyama M, Kusudo K, Shiraishi K, Iwaki T, Komatsu T, Hirai Y, Sato T, Kimura M, Yasukawa T, Kimura M, Taniguchi M, Shimoda Y, Kobayashi Y, Tsukioki M, Manabe N, Ando E, Kosaka M, Tsukiji T, Tokura C, Asao Y, Sugiyama M, Seto K, Okayama Research Investigation Organizing Network i. Current ventilator and oxygen management during general anesthesia: a multicenter, cross-sectional observational study. Anesthesiology. 2018;129(1):67-76.

15. Staehr-Rye AK, Meyhoff CS, Scheffenbichler FT, Vidal Melo MF, Gatke MR, Walsh JL, Ladha KS, Grabitz SD, Nikolov MI, Kurth T, Rasmussen LS, Eikermann M. High intraoperative inspiratory oxygen fraction and risk of major respiratory complications. Br J Anaesth. 2017;119(1):140-9.

16. Greif R, Akca O, Horn EP, Kurz A, Sessler DI, Outcomes Research G. Supplemental perioperative oxygen to reduce the incidence of surgical-wound infection. N Engl J Med. 2000;342(3):161-7.

17. Belda FJ, Aguilera L, Garcia de la Asuncion J, Alberti J, Vicente R, Ferrandiz L, Rodriguez R, Company R, Sessler DI, Aguilar G, Botello SG, Orti R, Spanish Reduccion de la Tasa de Infeccion Quirurgica G. Supplemental perioperative oxygen and the risk of surgical wound infection: a randomized controlled trial. JAMA. 2005;294(16):2035-42.

18. Myles PS, Leslie K, Chan MT, Forbes A, Paech MJ, Peyton P, Silbert BS, Pascoe E, Group ET. Avoidance of nitrous oxide for patients undergoing major surgery: a randomized controlled trial. Anesthesiology. 2007;107(2):221-31.

19. Myles PS, Peyton P, Chan MT, Leslie K, investigators E-I. Nitrous oxide in general anaesthesia - Authors' reply. Lancet. 2015;385(9966):417-8.

20. Meyhoff CS, Wetterslev J, Jorgensen LN, Henneberg SW, Hogdall C, Lundvall L, Svendsen PE, Mollerup H, Lunn TH, Simonsen I, Martinsen KR, Pulawska T, Bundgaard L, Bugge L, Hansen EG, Riber C, Gocht-Jensen P, Walker LR, Bendtsen A, Johansson G, Skovgaard N, Helto K, Poukinski A, Korshin A, Walli A, Bulut M, Carlsson PS, Rodt SA, Lundbech LB, Rask H, Buch N, Perdawid SK, Reza J, Jensen KV, Carlsen CG, Jensen FS, Rasmussen LS, Group PT. Effect of high perioperative oxygen fraction on surgical site infection and pulmonary complications after abdominal surgery: the PROXI randomized clinical trial. JAMA. 2009;302(14):1543-50.

21. Kurz A, Fleischmann E, Sessler DI, Buggy DJ, Apfel C, Akca O, Factorial Trial I. Effects of supplemental oxygen and dexamethasone on surgical site infection: a factorial randomized trialdouble dagger. Br J Anaesth. 2015;115(3):434-43.

22. Kurz A, Kopyeva T, Suliman I, Podolyak A, You J, Lewis B, Vlah C, Khatib R, Keebler A, Reigert R, Seuffert M, Muzie L, Drahuschak S, Gorgun E, Stocchi L, Turan A, Sessler DI. Supplemental oxygen and surgical-site infections: an alternating intervention controlled trial. Br J Anaesth. 2018;120(1):117-26.

23. Ferrando C, Aldecoa C, Unzueta C, Belda FJ, Librero J, Tusman G, Suarez-Sipmann F, Peiro S, Pozo N, Brunelli A, Garutti I, Gallego C, Rodriguez A, Garcia JI, Diaz-Cambronero O, Balust J, Redondo FJ, de la Matta M, Gallego-Ligorit L, Hernandez J, Martinez P, Perez A, Leal S, Alday E, Monedero P, Gonzalez R, Mazzirani G, Aguilar G, Lopez-Baamonde M, Felipe M, Mugarra A, Torrente J, Valencia L, Varon V, Sanchez S, Rodriguez B, Martin A, India I, Azparren G, Molina R, Villar J, Soro M. Effects of oxygen on post-surgical infections during an individualised perioperative open-lung ventilatory strategy: a randomised controlled trial. Br J Anaesth. 2020;124(1):110-20.

24. Myles PS, Carlisle JB, Scarr B. Evidence for compromised data integrity in studies of liberal peri-operative inspired oxygen. Anaesthesia. 2019;74(5):573-84.
25. Hawkes N. Oxygen after surgery: review questions WHO advice that high levels reduce infection. BMJ. 2019;364:1777.

26. Wetterslev J, Meyhoff CS, Jorgensen LN, Gluud C, Lindschou $\mathrm{J}$, Rasmussen LS. The effects of high perioperative inspiratory oxygen fraction for adult surgical patients. Cochrane Database Syst Rev. 2015;6:CD008884.

27. Cohen B, Schacham YN, Ruetzler K, Ahuja S, Yang D, Mascha EJ, Barclay AB, Hung MH, Sessler DI. Effect of intraoperative hyperoxia on the incidence of surgical site infections: a metaanalysis. Br J Anaesth. 2018;120(6):1176-86.

28. Mattishent K, Thavarajah M, Sinha A, Peel A, Egger M, Solomkin J, de Jonge S, Latif A, Berenholtz S, Allegranzi B, Loke YK. Safety of $80 \%$ vs $30-35 \%$ fraction of inspired oxygen in patients undergoing surgery: a systematic review and meta-analysis. $\mathrm{Br} \mathrm{J}$ Anaesth. 2019;122(3):311-24.

29. Meyhoff CS, Jorgensen LN, Wetterslev J, Siersma VD, Rasmussen LS, Group PT. Risk of new or recurrent cancer after a high perioperative inspiratory oxygen fraction during abdominal surgery. $\mathrm{Br}$ J Anaesth. 2014;113(Suppl 1):i74-81.

30. Fonnes S, Gogenur I, Sondergaard ES, Siersma VD, Jorgensen LN, Wetterslev J, Meyhoff CS. Perioperative hyperoxia - Longterm impact on cardiovascular complications after abdominal surgery, a post hoc analysis of the PROXI trial. Int J Cardiol. 2016;215:238-43.

31. Iguchi N, Kosaka J, Iguchi Y, Evans RG, Bellomo R, May CN, Lankadeva YR. Systemic haemodynamic, renal perfusion and renal oxygenation responses to changes in inspired oxygen fraction during total intravenous or volatile anaesthesia. $\mathrm{Br} \mathrm{J}$ Anaesth. 2020;125(2):192-200.

32. Girardis M, Busani S, Damiani E, Donati A, Rinaldi L, Marudi A, Morelli A, Antonelli M, Singer M. Effect of conservative vs conventional oxygen therapy on mortality among patients in an intensive care unit: the oxygen-ICU randomized clinical trial. JAMA. 2016;316(15):1583-9.

33. Ridgeon E, Bellomo R, Myburgh J, Saxena M, Weatherall M, Jahan R, Arawwawala D, Bell S, Butt W, Camsooksai J, Carle C, Cheng A, Cirstea E, Cohen J, Cranshaw J, Delaney A, Eastwood G, Eliott S, Franke U, Gantner D, Green C, Howard-Griffin R, Inskip D, Litton E, MacIsaac C, McCairn A, Mahambrey T, Moondi P, Newby L, O'Connor S, Pegg C, Pope A, Reschreiter H, Richards B, Robertson M, Rodgers H, Shehabi Y, Smith I, Smith J, Smith N, Tilsley A, Whitehead C, Willett E, Wong K, Woodford C, Wright S, Young P. Validation of a classification system for causes of death in critical care: an assessment of inter-rater reliability. Crit Care Resusc. 2016;18(1):50-4.

34. Chu DK, Kim LH, Young PJ, Zamiri N, Almenawer SA, Jaeschke R, Szczeklik W, Schunemann HJ, Neary JD, Alhazzani W. Mortality and morbidity in acutely ill adults treated with liberal versus conservative oxygen therapy (IOTA): a systematic review and meta-analysis. Lancet. 2018;391(10131):1693-705.

35. Siemieniuk RAC, Chu DK, Kim LH, Guell-Rous MR, Alhazzani W, Soccal PM, Karanicolas PJ, Farhoumand PD, Siemieniuk JLK, Satia I, Irusen EM, Refaat MM, Mikita JS, Smith M, Cohen DN, Vandvik PO, Agoritsas T, Lytvyn L, Guyatt GH. Oxygen therapy for acutely ill medical patients: a clinical practice guideline. BMJ. 2018;363:k4169. https://doi.org/10.1136/bmj.k4169.

36. Rasmussen BS, Perner A, Wetterslev J, Meyhoff CS, Schjorring OL. Oxygenation targets in acutely ill patients: still a matter of debate. Lancet. 2018;392(10163):2436-7.

37. Mackle D, Bellomo R, Bailey M, Beasley R, Deane A, Eastwood G, Finfer S, Freebairn R, King V, Linke N, Litton E, McArthur C, McGuinness S, Panwar R, Young P. Conservative oxygen therapy during mechanical ventilation in the ICU. N Engl J Med. 2020;382(11):989-98.

38. Barrot L, Asfar P, Mauny F, Winiszewski H, Montini F, Badie J, Quenot JP, Pili-Floury S, Bouhemad B, Louis G, Souweine 
B, Collange O, Pottecher J, Levy B, Puyraveau M, Vettoretti L, Constantin JM, Capellier G. Liberal or conservative oxygen therapy for acute respiratory distress syndrome. N Engl J Med. 2020;382(11):999-1008.

39. Schjorring OL, Klitgaard TL, Perner A, Wetterslev J, Lange T, Siegemund M, Backlund M, Keus F, Laake JH, Morgan M, Thormar KM, Rosborg SA, Bisgaard J, Erntgaard AES, Lynnerup AH, Pedersen RL, Crescioli E, Gielstrup TC, Behzadi MT, Poulsen LM, Estrup S, Laigaard JP, Andersen C, Mortensen CB, Brand BA, White J, Jarnvig IL, Moller MH, Quist L, Bestle MH, Schonemann-Lund M, Kamper MK, Hindborg M, Hollinger A, Gebhard CE, Zellweger N, Meyhoff CS, Hjort M, Bech LK, Grofte T, Bundgaard H, Ostergaard LHM, Thyo MA, Hildebrandt T, Uslu B, Solling CG, Moller-Nielsen N, Brochner AC, Borup M, Okkonen M, Dieperink W, Pedersen UG, Andreasen AS, Buus L, Aslam TN, Winding RR, Schefold JC, Thorup SB, Iversen SA, Engstrom J, Kjaer MN, Rasmussen BS. Lower or higher oxygenation targets for acute hypoxemic respiratory failure. N Engl J Med. 2021;84:1301.

40. Young PJ. Effect of oxygen therapy on mortality in the ICU. N Engl J Med. 2021;384(14):1361-3.

41. Beasley R, Chien J, Douglas J, Eastlake L, Farah C, King G, Moore R, Pilcher J, Richards M, Smith S, Walters H. Thoracic society of Australia and New Zealand oxygen guidelines for acute oxygen use in adults: 'Swimming between the flags'. Respirology. 2015;20(8):1182-91.

42. O'Driscoll BR, Howard LS, Earis J, Mak V. British Thoracic Society Guideline for oxygen use in adults in healthcare and emergency settings. BMJ Open Respir Res. 2017;4(1):e000170.

43. Austin MA, Wills KE, Blizzard L, Walters EH, Wood-Baker R. Effect of high flow oxygen on mortality in chronic obstructive pulmonary disease patients in prehospital setting: randomised controlled trial. BMJ. 2010;341:c5462.

44. Rodrigo GJ, Rodriquez Verde M, Peregalli V, Rodrigo C. Effects of short-term $28 \%$ and $100 \%$ oxygen on $\mathrm{PaCO} 2$ and peak expiratory flow rate in acute asthma: a randomized trial. Chest. 2003;124(4):1312-7.

45. Perrin K, Wijesinghe M, Healy B, Wadsworth K, Bowditch R, Bibby S, Baker T, Weatherall M, Beasley R. Randomised controlled trial of high concentration versus titrated oxygen therapy in severe exacerbations of asthma. Thorax. 2011;66(11):937-41.

46. Wijesinghe M, Williams M, Perrin K, Weatherall M, Beasley R. The effect of supplemental oxygen on hypercapnia in subjects with obesity-associated hypoventilation: a randomized, crossover, clinical study. Chest. 2011;139(5):1018-24.

47. Young P, Mackle D, Bellomo R, Bailey M, Beasley R, Deane A, Eastwood G, Finfer S, Freebairn R, King V, Linke N, Litton E, McArthur C, McGuinness S, Panwar R. Conservative oxygen therapy for mechanically ventilated adults with sepsis: a post hoc analysis of data from the intensive care unit randomized trial comparing two approaches to oxygen therapy (ICU-ROX). Intensive Care Med. 2020;46(1):17-26.

48. Asfar P, Schortgen F, Boisrame-Helms J, Charpentier J, Guerot E, Megarbane B, Grimaldi D, Grelon F, Anguel N, Lasocki S, Henry-Lagarrigue M, Gonzalez F, Legay F, Guitton C, Schenck M, Doise JM, Devaquet J, Van Der Linden T, Chatellier D, Rigaud JP, Dellamonica J, Tamion F, Meziani F, Mercat A, Dreyfuss D, Seegers V, Radermacher P. Hyperoxia and hypertonic saline in patients with septic shock (HYPERS2S): a two-by-two factorial, multicentre, randomised, clinical trial. Lancet Respir Med. 2017;5(3):180-90

49. Sekhon MS, Ainslie PN, Griesdale DE. Clinical pathophysiology of hypoxic ischemic brain injury after cardiac arrest: a "two-hit" model. Crit Care. 2017;21(1):90.

50. Pilcher J, Weatherall M, Shirtcliffe P, Bellomo R, Young P, Beasley R. The effect of hyperoxia following cardiac arrest - A systematic review and meta-analysis of animal trials. Resuscitation. 2012;83(4):417-22.

51. Young P, Mackle D, Bellomo R, Bailey M, Beasley R, Deane A, Eastwood G, Finfer S, Freebairn R, King V, Linke N, Litton E, McArthur C, McGuinness S, Panwar R, Baker T, Hurford S, La Pine M, Mackle D, McInnes C, Navarra L, Pritchard A, Cruz RS, Turner A, Broadley T, King V, Lee D, Linke N, Reid L, Murray L, Blakemore A, Butler M, Cowdrey K-A, Gilder E, Hallion J, Long S, McGuinness S, Neal P, Parke R, Wallace S, Chen Y, McArthur C, McConnochie R, Newby L, Simmonds C, Bowie D, Burke B, Closey D, Crombie R, Davidson N, Greer A, Henderson S, Hitchings L, Knight D, Mehrtens J, Miller K, Minto E, Morgan S, Morris A, Parker K, Ritzema-Carter J, Roberts J, Sahl C, Shaw G, Townend K, Chadwick L, Chalmers D, Freebairn R, Park M, Park P, Rolls C, Chapman C, Stapleton A, Aguila J, Dias A, Kazemi A, Lai V, Song R, Williams T, Caniba S, Carpenter M, Dagooc R, Hacking D, Lawrey Y, Buehner U, Williams E, Albrett J, Jackson C, Marko P, Barry B, Beehre N, Dinsdale D, Edney S, Fitzjohn F, Hicks P, Hill G, Hunt A, Judd H, Latimer-Bell C, Lawrence C, Lesona E, McKay-Vucago A, Navarra L, Poynter C, Psirides A, Robertson Y, Smellie H, Cruz RS, Sturland S, Ure B, Young P, Board J, Burrell A, Byrne T, Dean E, Martin E, Mason C, McCracken P, Richardson S, Vallance S, Young M, Bellomo R, Eastwood G, Peck L, Young H, Eroglu E, Litton E, Palermo A, Pellicano S, Bihari S, Jin X, Laver R, Matheson E, Schwartz K, Shrestha T, Beckingham T, Soar N, Bhatia D, Bulfin L, Crozier T, Lavrans K, Luong J, Maduri V, Patterson M, Peppin C, Wang A, Kurenda C, Peake S, Robaa N, Williams P, Badek L, Bart S, Chapman M, Davies M, Deane A, Doherty S, Glasby K, Gluck S, Grieve R, Karr P, McIntyre J, O'Connor S, Poole A, Raith E, Reddi B, Rivett J, Sethi S, Yap J, Yeo N, Aliabdelhamind Y, Anstey J, Barge D, Byrne K, Deane A, Doherty S, Emery P, Forrest P, Haile M, Lussier S, Rechnitzer T, Wigmore G, Palermo A, Pellicano S, Regli A, Barbazza L, Dixon B, Holmes J, Santamaria J, Smith R, Tobin A, on behalf of the ICUROX Investigators and the Australian and New Zealand Intensive Care Society Clinical Trials Group. Conservative oxygen therapy for mechanically ventilated adults with suspected hypoxic ischaemic encephalopathy. Intensive Care Med. 2020;46:2411.

52. Neumar RW, Nolan JP, Adrie C, Aibiki M, Berg RA, Bottiger BW, Callaway C, Clark RS, Geocadin RG, Jauch EC, Kern KB, Laurent I, Longstreth WT, Jr., Merchant RM, Morley P, Morrison LJ, Nadkarni V, Peberdy MA, Rivers EP, Rodriguez-Nunez A, Sellke FW, Spaulding C, Sunde K, Vanden Hoek T. Post-cardiac arrest syndrome: epidemiology, pathophysiology, treatment, and prognostication. A consensus statement from the international liaison committee on resuscitation (American heart association, Australian and New Zealand council on resuscitation, European resuscitation council, heart and stroke foundation of Canada, InterAmerican heart foundation, resuscitation council of Asia, and the resuscitation council of Southern Africa); the American heart association emergency cardiovascular care committee; the council on cardiovascular surgery and anesthesia; the council on cardiopulmonary, perioperative, and critical care; the council on clinical cardiology; and the stroke council. Circulation. 2008;118(23):2452-83.

53. Young PJ, Bailey M, Bellomo R, Bernard S, Bray J, Jakkula P, Kuisma M, Mackle D, Martin D, Nolan JP, Panwar R, Reinikainen M, Skrifvars MB, Thomas M. Conservative or liberal oxygen therapy in adults after cardiac arrest: an individual-level patient data meta-analysis of randomised controlled trials. Resuscitation. 2020;157:15-22.

54. Guyatt GH, Oxman AD, Vist GE, Kunz R, Falck-Ytter Y, AlonsoCoello P, Schunemann HJ, Group GW. GRADE: an emerging consensus on rating quality of evidence and strength of recommendations. BMJ. 2008;336(7650):924-6. 
55. Jakkula P, Reinikainen M, Hastbacka J, Loisa P, Tiainen M, Pettila V, Toppila J, Lahde M, Backlund M, Okkonen M, Bendel S, Birkelund T, Pulkkinen A, Heinonen J, Tikka T, Skrifvars MB, group Cs. Targeting two different levels of both arterial carbon dioxide and arterial oxygen after cardiac arrest and resuscitation: a randomised pilot trial. Intensive Care Med. 2018;44(12):2112-21.

56. Bray JE, Smith K, Hein C, Finn J, Stephenson M, Cameron P, Stub D, Perkins GD, Grantham H, Bailey P, Brink D, Dodge $\mathrm{N}$, Bernard S, investigators E. The EXACT protocol: A multicentre, single-blind, randomised, parallel-group, controlled trial to determine whether early oxygen titration improves survival to hospital discharge in adult OHCA patients. Resuscitation. 2019;139:208-13.

57. Thomas M, Voss S, Benger J, Kirby K, Nolan JP. Cluster randomised comparison of the effectiveness of $100 \%$ oxygen versus titrated oxygen in patients with a sustained return of spontaneous circulation following out of hospital cardiac arrest: a feasibility study. PROXY: post ROSC OXYgenation study. BMC Emerg Med. 2019;19(1): 16 .

58. The Mega Randomised Registry Trial Comparing Conservative vs. Liberal OXygenation. Australian and New Zealand Clinical Trials Registry. https://www.anzctr.org.au/Trial/Registration/Trial Review.aspx ?id=379432. Accessed 29 July 2021.

59. Young PJ, Bellomo R. The risk of hyperoxemia in ICU patients: much Ado about O2. Am J Respir Crit Care Med. 2019;200:1333.

Publisher's Note Springer Nature remains neutral with regard to jurisdictional claims in published maps and institutional affiliations. 